\title{
Deciphering Hawaiian Magma Chambers Using Electron Microprobe Analyses
}

\author{
Ken Hon
}

Geology Department, University of Hawaii Hilo, 200 W. Kawili Street, Hilo, HI, 96720.

Volcanic eruptions by their very nature are disequilibrium, or at best quasi-equilibrium processes that are partially preserved by eruptive products. Many of these processes are recorded in minerals as changes in composition, which can be determined by EPMA. Working on actively erupting volcanoes allows samples to be collected with extremely high temporal resolution that provides important context for interpretation of processes. Samples can also be quenched to prevent the mineral and glass compositions from changing during normal post-emplacement cooling processes.

Kilauea Volcano has been in nearly continuous eruption for the past 22 years. For most of this eruption, magma has moved out of the main summit chamber and has been stored for days or weeks in local magma chambers beneath the vent. During a short period from mid-1986 to mid-1990, lava was erupted from the Kupaianaha lava lake with little or no local storage. Lava erupted from the lava lake provides the best record of processes within the summit magma chamber as there was little or no modification during local storage. Whole-rock XRF and EPMA glass analyses (Fig. 1) from this period show a broad set of positively correlated fluctuations in $\mathrm{MgO}$ content. These have been interpreted by previous workers as gradual changes in source composition or mixing at the base of the magma chamber during input of buoyant new melt [1,2]. Both models assume that the whole rock compositions reflect an original composition that has since cooled to a combination of melt (glass) and crystals (olivine) without losing or gaining olivine. This interpretation is consistent with olivine compositions that range from olivine in equilibrium with the whole rock melt and glasses.

Examination of the average olivine composition and calculated bulk olivine compositions suggest that the olivines were only in equilibrium with whole-rock compositions for a short period after the switch from episodic high fountain eruptions to continuous lava lake activity. By mid-1987, the bulk olivine composition is closer to being in equilibrium with the glass than the whole-rock composition, suggesting that some of the olivine in the rocks has been entrained from other sources.

Sulfur contents of glass inclusions within olivine crystals suggest that much of the olivine originated in the summit magma chamber (Fig. 2). The olivines with high sulfur inclusions also have a broad range of forsterite $(\mathrm{MgO})$ contents that indicate a strong roofward cooling gradient in the summit magma chamber $\left(1200-1170^{\circ} \mathrm{C}\right)$. This roofward cooling is accompanied by degassing of $\mathrm{SO}_{2}$ and probably $\mathrm{H}_{2} \mathrm{O}$ beneath Halemaumau Crater. Water loss increases the density of the magma and could produce descending plumes of magma that convectively stir the underlying chamber. An alternative theory for the origin of the broad sinusoidal $\mathrm{MgO}$ and temperature fluctuations is that they are related to the vigor of convection within the upper parts of the summit magma chamber.

[1] M.O. Garcia et al., J. Petrology, 41, no. 7 (2000) 967.

[2] C.R. Thornber, USGS PP 1676, (2003) 121.

[3] Aid of Hawaiian Volcano Observatory colleagues is gratefully acknowledged.

[4] This work was partially supported by NSF MRI Grant EAR-0116904 


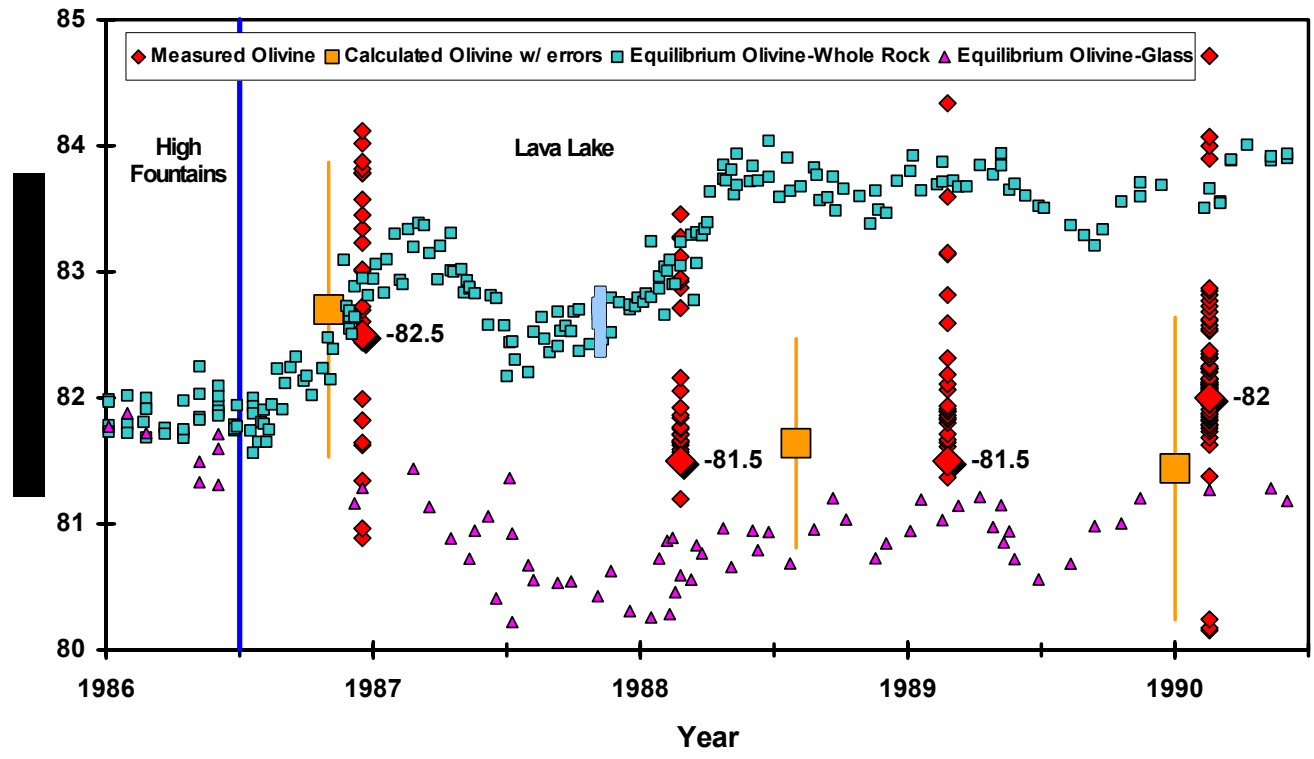

Figure 1. Plot of forsterite content $(\mathrm{MgO})$ of olivine versus time during the Kupaianaha stage (July 1986 to February 1992) of the current eruption. Measured compositions of olivines and their averages are shown as diamonds. Large squares are olivine values calculated by linear regression methods from changes in whole rock compositions due to addition or removal of olivine. The small squares are olivine compositions calculated to be in equilibrium with the whole rock analysis. Small triangles are olivine compositions calculated to be in equilibrium with glass compositions.

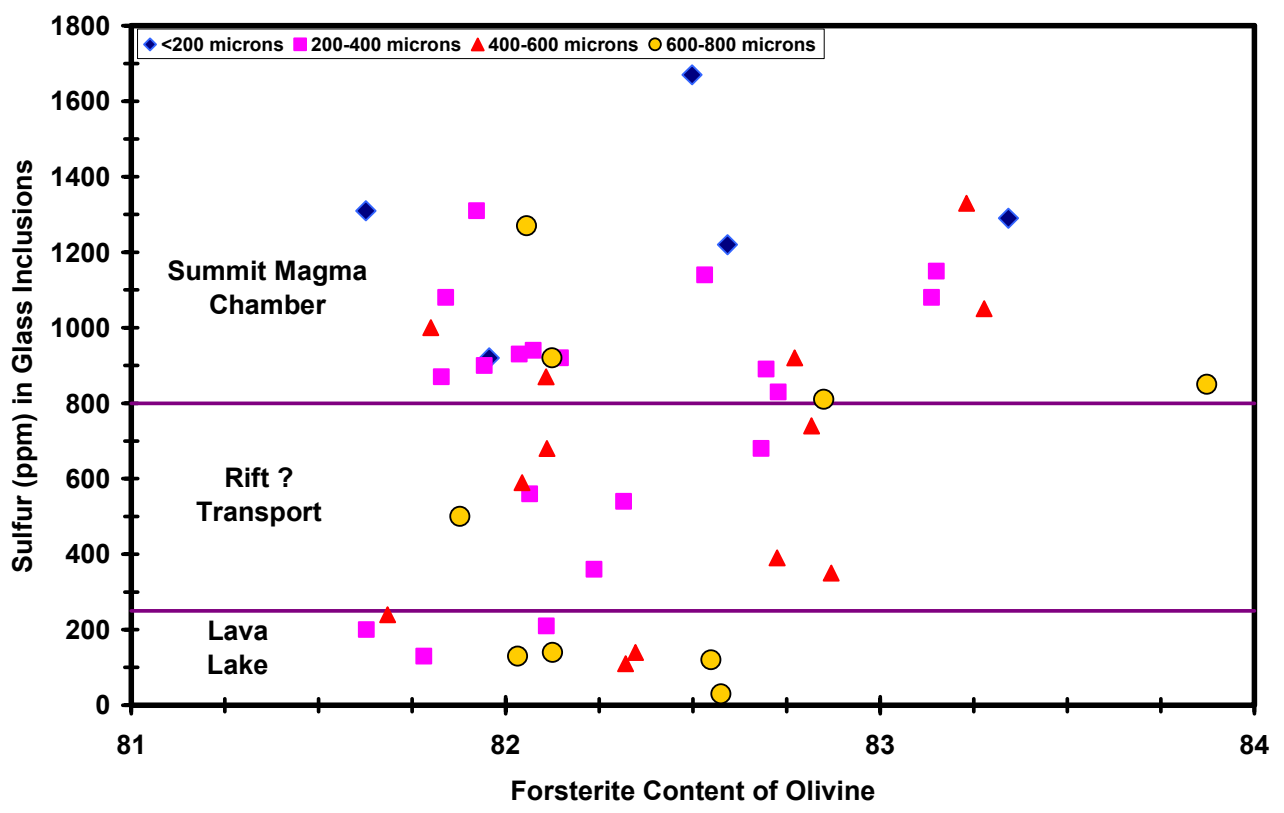

Figure 2. Sulfur content of glass inclusions in olivine versus the forsterite content of the olivine cores. Glass inclusions with sulfur $>800 \mathrm{ppm}$ are thought to have formed in the summit magma chamber. Glass inclusions with sulfur $<250 \mathrm{ppm}$ probably formed in the lava lake. Intermediate sulfur compositions may indicate formation during transport from the summit to the eruption site. 